\title{
Los cuentos motores como herramienta metodológica en las clases de Educación Física
}

\section{Cynthia Vázquez Carrasco}

\section{Graduada en Educación Primaria (Mención EF) en el CEU Cardenal Spínola (adscrito a la Universidad de Sevilla)}

\section{Email: cinthyvc@gmail.com}

\section{RESUMEN:}

En este artículo se incorpora una herramienta metodológica diferente en las clases de Educación Física de Primaria, los cuentos motores. Esta propuesta consiste en utilizar esta herramienta en los tres ciclos de Educación Primaria, más concretamente, en el segundo nivel del primer ciclo y en el primer nivel de segundo y tercer ciclo. Para conseguir todo esto, en primer lugar se realizó una revisión bibliográfica sobre el origen de esta metodología y sus características. A continuación, se propone un plan de intervención para un centro con un diseño y elaboración propia. Tras su puesta en práctica, se realizó un análisis a partir de los resultados obtenidos y de los datos recogidos durante la intervención: diario de prácticas, autoevaluación del alumnado implicado, rúbricas para la evaluación del alumnado, observación participante, toma de fotografías, etc. En las conclusiones se trata la alta complejidad que presenta este recurso para llevar a cabo en las aulas de Educación Primaria, y por qué es importante una buena formación al respecto.

PALABRAS ClAVE: Recurso Didáctico, Motricidad, Educación Primaria, Metodología. 


\section{INTRODUCCIÓN}

La educación está enfocada a la búsqueda del desarrollo integral del alumnado a través de metodologías multidisciplinares que engloben la mayoría de conocimientos posible. Por tanto, es necesario que los docentes obtengan la formación más completa posible. Por ello, en este artículo se propone el uso de una nueva herramienta metodológica, los cuentos motores, en un centro de carácter público en los tres ciclos de Educación Primaria que lo componen. Es por esto, que se presenta en este documento el diseño y elaboración de diferentes cuentos motores con el objetivo de llevarlos a la práctica y constatar la utilidad de este recurso, a partir de los resultados obtenidos.

Realizar innovaciones a través de esta herramienta metodológica, no solo enriquece al alumnado, sino también al profesorado. Como nos dice West (1990, citado por Edwards, 2009) el término de innovación educativa es "introducción intencional y aplicación en un rol, grupo u organización, de ideas, procesos, productos o procedimientos, diseñados para beneficiar perceptiblemente al individuo, al grupo, la organización o a la sociedad en su conjunto". El uso del cuento motor en las clases de Educación Física (EF) de Primaria no es algo completamente nuevo o desconocido para todo el equipo de docentes que imparten Educación Física, pero sí es una herramienta poco utilizada. De hecho, ningún docente del centro donde se llevó a cabo la intervención lo solía utilizar por lo que supuso una innovación docente.

El cuento motor es un recurso educativo que tradicionalmente se ha empleado en la etapa de Educación Infantil. En este sentido, la mayoría de documentación que se ha consultado al respecto está centrada en los cuentos motores para educación infantil o para los primeros ciclos de primaria. Pero ¿se podría utilizar con éxito en tercer ciclo? Ese fue uno de los retos e esta intervención, emplear el cuento motor en todos los ciclos de Primaria.

\subsection{Definición de cuentos motores}

Para conocer la definición de cuento motor, primero, se debe conocer la definición del cuento tradicional. Molina (2008) define el cuento como "una narración breve, oral o escrita, de un suceso imaginario". Dentro de los diferentes tipos de cuentos que podemos encontrar, tenemos los cuentos motores, en los cuáles intervienen acciones motrices. Conde (2001, citado por Iglesia, 2008, p.3), afirma que un cuento motor puede ser definido como "cuento jugado, un cuento vivenciado de manera colectiva, con unas características y unos objetivos propios". Es de vital importancia conocer que los cuentos motores son un vehículo esencial para la construcción del pensamiento del niño (Conde y Viciana, 1999).

Se entiende por tanto, que un cuento motor, jugado o vivenciado, es aquel que a través de una narración breve, pero con un hilo argumental sencillo en un escenario inventado donde todos los alumnos adquieren roles de diferentes personajes y se sienten identificados con ellos, creándose propuestas donde los alumnos participan desde la acción motriz con un objetivo concreto.

\subsection{Características de los cuentos motores}

Los cuentos motores tienen una serie de características muy estructuradas que se marcan a continuación, según nos explica Conde (1994):

- Es un eslabón previo al cuento escrito y puede ir paralelo al cuento narrado. 
- Incide directamente en la capacidad expresiva de los niños (primero interpreta cognitivamente y luego motrizmente).

- El niño, cuando ejecuta el cuento motor, se convierte en protagonista absoluto.

- El cuento motor es una fuente motivadora que despierta en los niños el interés por descubrir historias y personajes, y les ayuda a introducirse en los caminos sorprendentes de los libros del teatro y compara con otras formas de entretenimiento menos participativas.

Por su parte, Vargas y Carrasco (2006) defienden que este tipo de cuentos debe contemplar las siguientes características:

- Los cuentos motores deben realizarse en un grupo poco numeroso de niños. Puede oscilar entre 10 y 20, con posibles variaciones.

- El profesor ha de haber leído el cuento con anterioridad, con el objeto de no entorpecer la dinámica si tiene que detenerse mucho para retomar los contenidos.

- La duración de las sesiones de los cuentos motores no debe ser muy extensa: diez-veinte minutos con los más pequeños; y de veinte- cuarenta con los más mayores.

- Si hay mucho cansancio, establecer pausas.

- Los cuentos deben tener forma de sesión.

- Puede suceder que en algún cuento motor las respuestas de los niños desemboquen hacia otros contenidos que rompan la dinámica que lleva el cuento que se pretende escenificar. Se debe respetar esta actitud siempre que el control del grupo esté garantizado y se advierta una aplicación pedagógica al protagonismo que haya suscitado esa modificación. En cualquier momento el profesor podrá retomar el hilo del cuento.

- Al finalizar el cuento, es conveniente mantener una charla con los niños.

- A partir del cuento motor, se pueden crear una serie de actividades paralelas como realizar dibujos sobre las situaciones del cuento, reproducir los personajes con plastilina, construir murales, canciones en torno al cuento, etc.

Además, según Ruiz (2011) existen cuentos que se trabajan de forma paralela a los cuentos motores, implicando, por partes iguales, el cuerpo y el movimiento de éste. Presentan leves diferencias, como puede ser la presencia de juegos (cuento jugado), tener la capacidad de contarlo sin tener un principio y un final (relato motor), resaltar las vivencias que han experimentado los alumnos (cuento vivenciado).

\subsection{Origen de los cuentos motores}

Según Thulin (1910, citado por Arguedas, 2006) el cuento vivenciado se origina en las clases de Educación Física con un único objetivo, "enriquecer las actividades realizadas para la población infantil más pequeña". Thulin defendía, que este consistía en "la unión de un tema de la vida diaria con un cuento; ambos se integraban mediante una serie de ejercicios y movimientos, que permitían la formación de un todo coherente". Siguiendo en esta línea, Zagalaz (2001, citado por Méndez-Giménez y Fernández-Río, 2013) afirma que los primeros cuentos motores parecen tener su origen en los "cuentos-gimnásticos" o "cuentos-ejercicios" de J. G. Thulin, quien en la primera mitad del siglo XX introdujo sus aportaciones sobre el cuento jugado al campo pedagógico de la Escuela Neo-sueca, con el propósito de enriquecer las actividades gimnásticas dirigidas a la población infantil. Sin embargo, son pocos los autores que han seguido investigando en este campo a pesar de todas las posibilidades metodológicas que nos ofrece en las aulas de Educación Física (EF). 


\subsection{Formación del profesorado}

En un artículo de Méndez-Giménez y Fernández-Río (2013) se abordó la formación inicial sobre cuentos motores en estudiantes del Grado de Primaria e Infantil (de la Universidad de Oviedo). El estudio consistió en realizar una intervención de aprendizaje basada en el diseño de un cuento motor, teniendo marcados tres objetivos: percepciones de los futuros docentes acerca del cuento motor; en qué medida se ven afectadas el diseño e invención de un cuento motor; comparar los resultados entre los futuros docentes de Infantil y Primaria. Tras realizar estas comparaciones, Méndez-Giménez y Fernández-Río (2013) obtuvieron que los futuros docentes de Infantil estaban más sensibilizados en los beneficios de éstos, mientras que los de Primaria apenas fueron capaces de realizarlos o lo hicieron con mucha dificultad. Este estudio muestra que la formación del profesorado de EF se encuentra con muchas lagunas en el área de los cuentos motores, por lo que sería interesante comprobar su utilidad en Primaria y formar mejor a los futuros maestros al respecto.

\subsection{El cuento motor como recurso didáctico}

Según Bettleheim (1995), el cuento motor es considerado una buena herramienta pedagógica, manteniendo la atención del niño, así como potenciando su curiosidad. En esta misma línea, Conde (1999) nos dice que "el cuento es una forma básica y esencial en la vida un niño. El cuento refuerza la capacidad de imaginar."

Tal y como se ha visto con anterioridad, los cuentos motores se consideran una herramienta metodológica muy atractiva y variada, que cuenta con múltiples ventajas: permiten trabajar diferentes contenidos, el niño se convierte en el protagonista, fomentan la creatividad, mejoran la capacidad expresiva y la motivación (Conde, 1994). Es cierto, que es algo más común el empleo del cuento motor en los primeros cursos de primaria, pero también puede ser una buena herramienta en los cursos superiores; aunque no es muy común que se lleve a la práctica por la alta complejidad que presenta su elaboración y el hecho de llevarlo a la práctica.

\subsection{El cuento motor en la programación}

El cuento motor es recomendado por algunos autores (Conde, 1994; Ruiz, 2011) como una herramienta metodológica más a tener en cuenta y a incluir en las programaciones de EF en la etapa de Educación Primaria.

No todas las unidades didácticas o las sesiones deben enfocarse desde esta perspectiva metodológica, puesto que lo nuevo puede convertirse en una rutina, provocando la monotonía en los alumnos. Sería una buena idea, iniciar cada unidad didáctica o cada sesión cuando consideremos que sea necesario resolver problemas, como por ejemplo: si nos encontramos con dos alumnos que están peleados. Podemos diseñar una dinámica en la que adquieran roles, como parte de un cuento motor, para solventar el problema como medianamente se pueda. Para que todo esto tenga sentido y podamos llevar a cabo estas sesiones, debemos tener en cuenta unos criterios metodológicos, como los establecidos por Martínez (2007, citado por Iglesia, 2008):

- El docente debe conocer muy bien el cuento.

- Disponer a priori del material que se vaya a utilizar y preparar su ubicación y utilidad.

- Disponer de un espacio amplio y/o abierto.

- Integrarse como uno más en la práctica de la actividad. 
- Sesión dividida en tres partes bien diferenciadas (fase de animación, fase principal y vuelta a la calma)

- Finalizada la sesión, podemos mantener una charla con los niños/as y trabajar otros contenidos más relacionados con la compresión y expresión oral.

- Esta actividad genera muchas otras actividades que podemos aprovechar según los intereses y las circunstancias.

Tras revisar la literatura científica en castellano, cabe destacar la importancia de algunos autores que han escrito manuales sobre los cuentos motores (Conde, 1999; Del Barrio et al., 2011; Ruiz, 2011). Así en la Tabla 1, se recoge una comparativa entre algunos aspectos que recogen estos autores sobre el cuento motor. En este sentido, destaca que ninguno de los autores utiliza los cuentos motores en el tercer ciclo; por lo que en este trabajo se realizará una propuesta para este ciclo. Por otra parte, la evaluación también es muy diferente según el autor que tratemos y el sistema evaluativo que queramos seguir. Sin embargo, todos coinciden en que los contenidos de los cuentos motores deben trabajarse de una forma globalizadora y con una estructura de sesión determinada, para conseguir todos los objetivos propuestos para ello.

Tabla 1. Comparativa de los principales autores sobre cuentos motores

\begin{tabular}{|c|c|c|c|c|}
\hline & & & & \\
\hline & Conde $(1994,1999)$ & \multicolumn{2}{|l|}{ Ruiz (2011) } & $\begin{array}{l}\text { Del Barrio et al. } \\
\text { (2011) }\end{array}$ \\
\hline $\begin{array}{l}\text { Destinatarios } \\
\text { en sus cuentos } \\
\text { motores. }\end{array}$ & $\begin{array}{l}\text { Segundo ciclo de } \\
\text { Educación Infantil y } \\
\text { primer ciclo de } \\
\text { Primaria, aunque en } \\
\text { ocasiones trabaja } \\
\text { con los niños del } 2^{\circ} \\
\text { ciclo }\end{array}$ & \multicolumn{2}{|c|}{$\begin{array}{l}\text { A partir del primer ciclo de } \\
\text { Educación Primaria }\end{array}$} & $\begin{array}{l}\text { Sólo el primer ciclo de } \\
\text { Educación Primaria }\end{array}$ \\
\hline $\begin{array}{l}\text { Características } \\
\text { de los cuentos }\end{array}$ & $\begin{array}{l}\text { El grupo no debe ser } \\
\text { numeroso, corta } \\
\text { duración, pausas, } \\
\text { que tenga } \\
\text { coherencia } \\
\end{array}$ & \multicolumn{2}{|c|}{$\begin{array}{c}\text { Se basa en una historia } \\
\text { simple con un argumento } \\
\text { sencillo, con protagonistas y } \\
\text { corta duración }\end{array}$} & $\begin{array}{l}\text { Adaptan cuentos } \\
\text { populares, conocidos } \\
\text { por todos los niños } \\
\text { para motivarlos }\end{array}$ \\
\hline Legislación & $\begin{array}{l}\text { Se basa en la } \\
\text { LOGSE. Los } \\
\text { objetivos son } \\
\text { globales }\end{array}$ & \multicolumn{2}{|c|}{$\begin{array}{c}\text { Se basa en la LOE. Pretende } \\
\text { fomentar la cooperación y } \\
\text { fomentar la autonomía y } \\
\text { lenguaje corporal }\end{array}$} & $\begin{array}{l}\text { Se basa en la LOE. } \\
\text { Los objetivos } \\
\text { utilizados son los de } \\
\text { etapa (EP) y los de } \\
\text { área (EF) }\end{array}$ \\
\hline $\begin{array}{l}\text { Contenidos } \\
\text { cuentos } \\
\text { motores } \\
\end{array}$ & \multicolumn{4}{|c|}{ Se trabajan de forma globalizada } \\
\hline $\begin{array}{l}\text { ¿Cómo } \\
\text { estructuran la } \\
\text { sesión? }\end{array}$ & $\begin{array}{l}\text { Calentamiento, } \\
\text { parte central, vuelta } \\
\text { a la calma, puesta } \\
\text { en común }\end{array}$ & $\begin{array}{c}\text { Asamblea inicial, acción } \\
\text { motriz, asamblea final }\end{array}$ & & $\begin{array}{l}\text { nación, parte principal, } \\
\text { a a la calma, momento } \\
\text { de reflexión }\end{array}$ \\
\hline \multirow[b]{2}{*}{ Método } & \multicolumn{4}{|c|}{ Fomentan el aprendizaje significativo a través de los cuentos motores } \\
\hline & $\begin{array}{c}\text { Sesiones dirigidas y } \\
\text { globalizada }\end{array}$ & Sesiones semi-dirigidas & \multicolumn{2}{|r|}{ Sesiones cooperativa } \\
\hline Evaluación & $\begin{array}{l}\text { No establece } \\
\text { ninguna }\end{array}$ & $\begin{array}{c}\text { Momentos de reflexión } \\
\text { y observación. Fichas } \\
\text { de seguimiento, } \\
\text { autoevaluación del } \\
\text { alumno }\end{array}$ & \multicolumn{2}{|c|}{$\begin{array}{c}\text { Se eligen los objetivos y se } \\
\text { llevan a cabo en las } \\
\text { actividades. Se realizan } \\
\text { rúbricas tanto para el } \\
\text { profesor como para los }\end{array}$} \\
\hline
\end{tabular}




\begin{tabular}{|c|c|c|c|}
\hline & & alumnos \\
\hline $\begin{array}{c}\text { ¿Cuál es el rol } \\
\text { del maestro? }\end{array}$ & $\begin{array}{c}\text { Leer el cuento y } \\
\text { conocerlo }\end{array}$ & $\begin{array}{c}\text { Leer el cuento o } \\
\text { contarlo sin necesidad } \\
\text { de tenerlo delante }\end{array}$ & $\begin{array}{c}\text { Se considera dinámico, } \\
\text { puesto que propone } \\
\text { actividades }\end{array}$ \\
\hline
\end{tabular}

\subsection{Objetivos}

El objetivo principal de este trabajo fue elaborar una propuesta de enseñanza, dinámica y atractiva, utilizando el cuento motor como herramienta metodológica enfocado a todos los ciclos de Primaria. Además, se propusieron una serie de objetivos más específicos:

- Revisar en diferentes fuentes bibliográficas el uso del cuento motor en las clases de Primaria y la formación del profesorado al respecto.

- Diseñar varios cuentos motores en función del curso y gusto de los alumnos con el fin de incentivarlos a participar en las sesiones.

- Evaluar la puesta en práctica de un cuento motor por ciclo, concretamente, en el segundo nivel del primer ciclo y primer nivel del segundo y tercer ciclo.

A continuación, se presenta el desarrollo de la propuesta de intervención.

\section{DESARROLLO DE LA INTERVENCIÓN CON LOS CUENTOS MOTORES}

\subsection{Destinatarios}

Las propuestas de intervención diseñadas han tenido por destinatarios alumnos de diversas índoles: segundo nivel de primer ciclo de primaria, primer nivel de segundo ciclo y primer nivel de tercer ciclo. Todos ellos pertenecían a un C.E.I.P público de un pueblo perteneciente a la provincia de Sevilla. Se eligió un curso de cada ciclo para experimentar cómo repercute esta herramienta metodológica en las diferentes edades.

Cada grupo de los que han sido objetos de estas sesiones posee unas características propias, que necesitan de algunas adaptaciones y que se muestran en la Tabla 2:

Tabla 2. Características del alumnado donde se llevó a cabo la intervención

\begin{tabular}{|c|c|c|c|}
\hline & $2^{\circ}$ de Primaria & $3^{\circ}$ de Primaria & 5o de Primaria \\
\hline Asmáticos & 实 & & \\
\hline Diabetes tipo II & & & $\$$ \\
\hline TDAH con hiperactividad & 2 & 2 & \\
\hline Problemas de personalidad & & 23 & $\sqrt{3}$ \\
\hline Retraso psicomotor & $\$$ & & \\
\hline $\begin{array}{l}\text { Alumnos inmigrantes con } \\
\text { problemas de integración }\end{array}$ & & & \\
\hline
\end{tabular}

Esta propuesta de intervención se llevó a cabo con un total de 171 estudiantes de Primaria, pudiendo observar los resultados en las diferentes edades. Este trabajo 
se llevó a cabo durante el período de prácticas del Grado en Educación Primaria (Mención en EF).

\subsection{Procedimiento y diseño de actividades para la propuesta de intervención}

En primer lugar, se solicitó la colaboración del maestro de EF (tutor interno de las prácticas) responsable de los grupos. Se llegó al acuerdo de realizar dos sesiones por nivel involucrado. Una vez conseguido el consentimiento por parte del tutor, se le entrega al director del centro una carta pidiendo su autorización para llevarlas a cabo, así como para la toma de fotografías y la administración de un cuestionario sobre los gustos para los alumnos de quinto nivel (anexado a la carta). El director se mostró de acuerdo y se continuó con el procedimiento. Posteriormente, se entregaron las autorizaciones para la toma de fotografías y realización del cuestionario a los padres/tutores. Los datos obtenidos con los cuestionarios fueron empleados para elaborar cuentos motores acordes a sus gustos, conseguir motivarlos y mejorar su participación en las clases de EF. Utilizando esta información, se pasó al diseño de los cuentos acorde a todos los objetivos y contenidos de la unidad didáctica de cada nivel. Para las sesiones llevadas a la práctica se utilizaron historias de elaboración propia tituladas: "Queso y veneno", "Ratones y gatos" y "Indios y hombres de caballería". Por tanto, se realizaron un total de tres historias, una para cada ciclo de Educación Primaria (segundo, tercero y quinto nivel), la cual la conforman un total de 14 sesiones de las cuales seis (dos por cuento motor) han sido evaluadas para este trabajo. Cabe destacar que el número de sesiones evaluadas se debe al poco tiempo disponible durante el tiempo de prácticas y a la presencia de otro alumno de prácticas que también necesitaba llevarlas a cabo. Además de esto, alguno de los cuentos ha sufrido modificaciones por los problemas internos que se han observado en algunos cursos y que se ha aprovechado para trabajar desde los cuentos y así intentar solventarlos un poco mediante dinámicas para la resolución de resolución de conflictos.

Una vez realizados los cuentos, se realizó el diseño de los instrumentos de evaluación para los contenidos propuestos en las diferentes sesiones de los cuentos.

\subsection{Elaboración de los cuentos motores}

Este trabajo se basa en la creación y uso de cuentos motores, expuesto a través de metodología dirigida, fundamentadas a través de juegos basados en la historia. Estas actividades están enfocadas desde una metodología semi-abierta, como por ejemplo: tirar los papeles de manera libre por la pista. Algunas tareas trabajan la cooperación como por ejemplo, por equipos debemos obtener 20 puntos, obteniendo como resultado la mejora de la socialización entre compañeros y las actividades colectivas, aunque la mayoría se trabajan de manera individual o en pequeños grupos dependiendo de la disposición de todo el alumnado.

La utilización de esta metodología tiene en cuenta las características y el aprendizaje significativo por parte de los alumnos, como por ejemplo: los conocimientos previos sobre el reciclaje y la recogida de basura.

Para cada curso se trabaja una historia diferente para motivarlos según sus gustos y preferencias. Todo esto se basa en una metodología globalizadora donde los contenidos y objetivos están íntimamente relacionados. A su vez, es flexible, pues se tienen en cuenta las aportaciones de los alumnos al respecto, como por ejemplo: "quiero ser un perro, en lugar de una rata" (como comentó un alumno de segundo nivel). 


\subsection{Recursos}

Para realizar la planificación de los cuentos motores se han tenido en cuenta los recursos de los que el centro disponía, tal y como se muestra en la Tabla 3.

Tabla 4. Recursos utilizados en la elaboración de los cuentos motores

\begin{tabular}{|l|l|l|}
\hline \multicolumn{1}{|c|}{ Humanos } & \multicolumn{1}{|c|}{ Materiales } & \multicolumn{1}{c|}{ Espaciales } \\
\hline $\begin{array}{l}\text { Tres maestros (el maestro de } \\
\text { EF de } 2^{\circ} \text { a } 6^{\circ} \text { de EP y dos } \\
\text { alumnos de prácticas) }\end{array}$ & $\begin{array}{l}\text { Bolas de papel recicladas, } \\
\text { cartones, bolsas, pelotas, zonas de árboles y aula } \\
\text { aros, picas, hoja de de clase. } \\
\text { autoevaluación, etc. }\end{array}$ & $\begin{array}{l}\text { zonas } \\
\text { de }\end{array}$ \\
\hline
\end{tabular}

\subsection{Temporalización}

Las sesiones se llevaron a cabo a lo largo de la última semana de abril y la primera semana de mayo del 2014. Cada una de las sesiones se ha realizado en el marco de una hora aproximadamente, exceptuando las sesiones en el tercer ciclo, que tienen una duración de una hora y media aproximadamente. A continuación, en la Tabla 5 se desglosa el cronograma utilizado para la intervención y una valoración general del desarrollo de la sesión, en la que se empleó una escala cualitativa (Muy Bien - Bien - Regular - Mal - Muy Mal). Para dicha valoración general, se tendrá en cuenta toda la sesión, desde la organización de materiales, del tratamiento de la información, objetivos, ritmos de aprendizaje, adaptaciones curriculares, programación y lo sucedido a raíz de todo esto.

Tabla 5. Cronograma de las diferentes sesiones realizadas

\begin{tabular}{|c|c|c|c|}
\hline $\begin{array}{l}\text { Fecha de } \\
\text { exposición }\end{array}$ & Sesión y cuento & Nivel & Resultado \\
\hline 22-04-14 & S.1: Queso y veneno. & \multirow{2}{*}{$2^{\circ} \mathrm{A}$} & Regular \\
\hline $22-04-14$ & S.2: Queso y veneno. & & Muy bien \\
\hline 22-04-14 & S.1: Queso y veneno. & \multirow{2}{*}{$2^{\circ} \mathrm{B}$} & Regular \\
\hline $22-04-14$ & S.2: Queso y veneno. & & Muy bien \\
\hline $23-04-14$ & S.1: Queso y veneno. & \multirow{2}{*}{$2^{\circ} \mathrm{C}$} & Muy bien \\
\hline $30-04-14$ & S.2: Queso y veneno. & & Muy bien \\
\hline $30-04-14$ & S.1: Ratones y gatos. & \multirow{2}{*}{$3^{\circ} \mathrm{A}$} & Regular \\
\hline $30-04-14$ & S.2: Ratones y gatos. & & Regular \\
\hline 05-04-14 & S.1: Ratones y gatos. & \multirow{2}{*}{$3^{\circ} \mathrm{B}$} & Muy bien \\
\hline $05-05-14$ & S.2: Ratones y gatos. & & Muy bien \\
\hline $08-05-14$ & S.1: Indios y hombres de caballería. & \multirow{2}{*}{$5^{\circ} \mathrm{A}$} & Muy bien \\
\hline 08-05-15 & S.2: Indios y hombres de caballería. & & Muy bien \\
\hline $08-05-14$ & S.1: Indios y hombres de caballería. & \multirow{2}{*}{$5^{\circ} \mathrm{B}$} & Muy bien \\
\hline 08-05-15 & S.2: Indios y hombres de caballería. & & Regular \\
\hline
\end{tabular}

\subsection{Temas transversales}

Los elementos transversales podemos encontrarlos tanto el artículo 10 del Real Decreto 126/2014, como en el artículo 5 del Decreto 97/2015; en este artículo se propone trabajar el fomento a la lectura y la educación en valores como el respeto, la cooperación, la coeducación, la moralidad, la educación para la paz, etc., además de la educación ambiental, priorizando el reciclaje en la historia de "Queso y Veneno". 


\subsection{Atención a la diversidad y adaptaciones curriculares para los niños con necesidades educativas especiales (NEE)}

Lo ideal para proporcionar una atención individualizada al alumnado, fue la intervención del segundo y tercer maestro (en este caso, el otro alumno de prácticas). Este maestro dedicó el tiempo de la sesión para apoyar a los niños que lo necesitaban, ayudándoles a participar, a que no se quedasen sin pareja, a mantener la atención en la historia, etc.; para así conseguir los objetivos propuestos, para todos ellos, en la unidad didáctica del cuento motor. A pesar que estos niños requirieron de un poco más de ayuda, los objetivos fueron los mismos para todos los alumnos aunque se hizo una leve modificación a la hora de la evaluación.

\subsection{Metodología de análisis e interpretación de información}

Los instrumentos utilizados para obtener información sobre la intervención o la puesta en práctica de los cuentos motores fueron:

- Evaluación del alumnado de las sesiones: consistió en una ficha que se entregó a cada alumno al final de las sesiones de cuentos motores. En ella se encuentran preguntas sobre qué parte les ha gustado más, cuál menos, etc.; con el objetivo de evaluar el cuento y la misma participación de los alumnos.

- Rúbrica: una escala descriptiva dedicada a cada alumno, en la que se evaluó los objetivos principales propuestos en la unidad didáctica.

- Sesiones del diario de prácticas, que versan sobre las sesiones de los cuentos motores. En ella se recogieron con detalle todos los pasos, problemas y aspectos positivos que han aparecido en todas las sesiones relacionadas con esta temática.

- Autoevaluación o percepción subjetiva del docente, donde se realizó una valoración general del desarrollo de cada sesión, en la que se empleó una escala cualitativa con las siguientes opciones de respuesta: Muy Bien - Bien Regular - Mal - Muy Mal.

\subsection{Propuesta de intervención para primer ciclo}

En esta propuesta para el primer ciclo se trabaja el cuento motor de "Queso y veneno" enfocado al segundo nivel de primer ciclo.

\section{Introducción}

En esta unidad, se trataron todos los bloques de contenidos del área de Educación Física a través de una herramienta metodológica poco utilizada en las clases de Educación Física, el cuento motor.

El objetivo primordial de esta unidad, no es otro más que los alumnos tomen conciencia de la importancia del medio ambiente, así como la interpretación de un cuento en el que se encontrarán una amplia batería de actividades.

\section{Objetivos}

\begin{tabular}{|c|l|c|c|c|}
\hline \multicolumn{2}{|c|}{ Concreción de objetivos didácticos } & $\begin{array}{c}\text { Vinculación } \\
\text { OGA }\end{array}$ & $\begin{array}{c}\text { Vinculación } \\
\text { OGE }\end{array}$ & Competencias \\
\hline 1 & $\begin{array}{l}\text { Practicar diferentes formas de } \\
\text { desplazamientos y diferentes }\end{array}$ & $\begin{array}{c}1,2 \text { y } 5 ; \\
\text { Educación }\end{array}$ & A, B, C & $\begin{array}{c}\text { Comunicación } \\
\text { lingüística. }\end{array}$ \\
\hline
\end{tabular}




\begin{tabular}{|c|c|c|c|c|}
\hline & tipos de velocidades. & Física. & & \multirow{10}{*}{$\begin{array}{c}\text { Competencia } \\
\text { matemática y } \\
\text { competencias } \\
\text { básicas en ciencia } \\
\text { y tecnología. } \\
\text { Competencia } \\
\text { digital. } \\
\text { Aprender a } \\
\text { aprender. } \\
\text { Competencia social } \\
\text { y cívica. } \\
\text { Sentido de } \\
\text { iniciativa y espíritu } \\
\text { emprendedor. }\end{array}$} \\
\hline 2 & $\begin{array}{l}\text { Desarrollar la capacidad de } \\
\text { trabajar en grupo y autonomía. }\end{array}$ & $\begin{array}{l}1 \text { y } 5 \\
\text { Educación } \\
\text { Física. }\end{array}$ & $A, B, C$ & \\
\hline 3 & $\begin{array}{l}\text { Ejercitar las habilidades motrices } \\
\text { básicas. }\end{array}$ & $\begin{array}{l}\text { 1, } 2 \text { y } 4 \\
\text { Educación } \\
\text { Física. }\end{array}$ & A, B, C & \\
\hline 4 & $\begin{array}{l}\text { Reaccionar lo más rápido posible } \\
\text { ante un estímulo. }\end{array}$ & $\begin{array}{l}2 \text { y } 4 \\
\text { Educación } \\
\text { Física. }\end{array}$ & $B, C$ & \\
\hline 5 & $\begin{array}{l}\text { Interpretar una historia y adquirir } \\
\text { roles. }\end{array}$ & $\begin{array}{c}\text { 1, 2, 3, 4, 5, } \\
6 \text { y } 7 \\
\text { Educación } \\
\text { Física. }\end{array}$ & $\mathrm{B}, \mathrm{C}, \mathrm{E}$ & \\
\hline 6 & Aprender a jugar en equipo. & $\begin{array}{l}1,3 \text { y } 6 ; \\
\text { Educación } \\
\text { Física }\end{array}$ & $A, B$ & \\
\hline 7 & $\begin{array}{l}\begin{array}{l}\text { Respetar el material y } \\
\text { instalaciones. }\end{array} \\
\end{array}$ & $\begin{array}{l}\text { 6; Educación } \\
\text { Física }\end{array}$ & $\mathrm{K}, \mathrm{M}$ & \\
\hline 8 & Interiorizar el esquema corporal. & $\begin{array}{l}1,2 \text { y } 3 \\
\text { Educación } \\
\text { Física }\end{array}$ & $\mathrm{B}, \mathrm{K}$ & \\
\hline 9 & $\begin{array}{l}\text { Comprender y respetar las } \\
\text { normas de los juegos. }\end{array}$ & $\begin{array}{l}5 \text { y } 6 ; \\
\text { Educación } \\
\text { Física }\end{array}$ & $A, B$ & \\
\hline 10 & $\begin{array}{l}\text { Conseguir una actitud innovadora } \\
\text { en la resolución y estrategias de } \\
\text { las actividades. }\end{array}$ & $\begin{array}{l}4 \text { y } 6 ; \\
\text { Educación } \\
\text { Física }\end{array}$ & $A, B, M$ & \\
\hline
\end{tabular}

\section{Contenidos}

\begin{tabular}{|c|l|c|}
\hline \multicolumn{2}{|c|}{ Concreción y secuenciación de contenidos } & $\begin{array}{c}\text { Vinculación con } \\
\text { OBJETIVOS } \\
\text { DIDÁCTICOS }\end{array}$ \\
\hline 1 & Cuento “Queso y veneno" & 3,5 \\
\hline 2 & Conocer diferentes tipos de desplazamientos y tipos de velocidades. & $1,2,3,4$ \\
\hline 3 & Participación y comprensión de reglas de juego y del aula. & $7,9,10$ \\
\hline 4 & El medio ambiente & 2 \\
\hline 5 & Ejecución de los juegos adecuado para el desarrollo del mismo. & $1,6,9$ \\
\hline 6 & $\begin{array}{l}\text { Descubrimiento y exploración de las posibilidades expresivas del } \\
\text { cuerpo y del movimiento. }\end{array}$ & $1,2,6,8$ \\
\hline
\end{tabular}

\section{Metodología}

En todos los cursos en los que se llevó a cabo estas unidades didácticas (primer, segundo y tercer ciclo), se siguió las siguientes pautas: se subió al aula a recoger a los alumnos y se le dieron las nociones previas sobre la sesión y aquella información que se consideró más importante. Al bajar al patio, en la primera sesión, se dividieron a los alumnos en grupos y se pintaron la cara para caracterizarse; y en la segunda, se comenzó con una asamblea para recordar lo trabajado en la sesión anterior. Posteriormente se pasó a la práctica, concluyendo por la recogida de material, realizando una reflexión final y montando una fila para subir de nuevo al aula.

El estilo de enseñanza que se utilizó en un comienzo fue el mando directo modificado para orientar a los alumnos en las actividades que estaban realizando. 
Después se pasó a emplear la resolución de problemas, en el que los alumnos experimentan las actividades enfocadas desde una perspectiva semi-abierta, en la que encontraremos alumnos que realizaron las actividades de forma diferente.

\section{Sesiones}

\begin{tabular}{|l|l|c|}
\hline UNIDAD DIDÁCTICA & Queso y veneno & 1 \\
\hline CURSO Y CICLO & Primer ciclo, segundo nivel & $\begin{array}{l}\text { Colchonetas, conos, picas, papeles, vasos de plástico, } \\
\text { aros,... }\end{array}$ \\
\hline MATERIAL & Individual y grupal. \\
\hline $\begin{array}{l}\text { METODOLOGÍA (№ DERTICIPANTES) } \\
\text { PARA }\end{array}$ &
\end{tabular}

PARTE INICIAL

DESCRIPCIÓN

REPRESENTACIÓN

Hace mucho tiempo en la ciudad de Ratolandia, sucedió algo que sorprendió a todos sus habitantes y quedó grabado en la historia. Eran las fiestas del pueblo, los ratones pequeños no tenían que ir a la escuela y los papás y las mamás ratones no iban al trabajo.

Repartiéndose por toda la zona señalizada con conos, se simula la fiesta en la que irán tirando intencionadamente papeles, periódicos,...

Todo el mundo estaba en la plaza, de fiesta: cantando, bailando, comiendo queso,...

Los alumnos harán lo que el profesor vaya dictando, como por ejemplo: comen (tiran los papeles al suelo), beben, bailan,... GRÁFICA

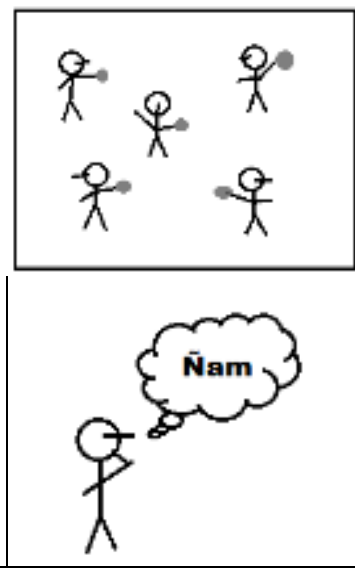

\section{PARTE PRINCIPAL}

Así que a la mañana siguiente todos los habitantes de Ratolandia, descubrieron con asombro que las calles estaban tan sucias que decidieron limpiarlas. Al no ponerse de acuerdo, dejaron que la basura fuera por sí sola a las papeleras, $y$, claro está, esto jamás ocurrió.

Dividimos lo que era la pista de baile en dos campos diferentes. El juego consiste en pasar la basura al campo contrario porque nadie la quiere en su campo.

Adaptación: Los niños con problemas motores pueden lanzar más cerca de la línea y se considera "cascarón de huevo".

\section{PARTE FINAL}

Hacer una reflexión final sobre la sesión.

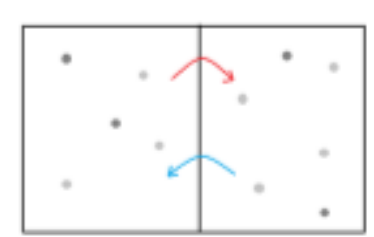

Hacer una reflexión final sobre la sesión. 


\begin{tabular}{|c|c|c|}
\hline UNIDAD DIDÁCTICA & Queso y veneno & 2 \\
\hline CURSO Y CICLO & \multicolumn{2}{|l|}{ Primer ciclo, segundo nivel } \\
\hline MATERIAL & \multicolumn{2}{|c|}{$\begin{array}{l}\text { Colchonetas, conos, picas, papeles, vasos de plástico, } \\
\text { aros,... }\end{array}$} \\
\hline $\begin{array}{l}\text { METODOLOGÍA (№ DE } \\
\text { PARTICIPANTES) }\end{array}$ & \multicolumn{2}{|l|}{ Individual y grupal. } \\
\hline \multicolumn{3}{|l|}{ PARTE PRINCIPAL } \\
\hline \multicolumn{2}{|c|}{ DESCRIPCIÓN } & $\begin{array}{l}\text { REPRESENTACIÓN } \\
\text { GRÁFICA }\end{array}$ \\
\hline \multicolumn{3}{|l|}{ Recordar la sesión anterior. } \\
\hline \multicolumn{3}{|l|}{ PARTE PRINCIPAL } \\
\hline \multicolumn{2}{|c|}{$\begin{array}{l}\text { El alcalde viendo que las ratas se iban apoderando cada } \\
\text { vez más de Ratolandia mandó colocar contenedores por } \\
\text { todo el pueblo y todos los ratones se pusieron de acuerdo } \\
\text { y recogieron todo utilizando los contenedores. Pero esa } \\
\text { noche no aparecieron los basureros a llevarse la basura, y } \\
\text { volvieron a japarecer las ratas! } \\
\text { Colocados en fila manteniendo los dos equipos anteriores, } \\
\text { pasamos por tres aros y cuando lleguemos al último deben } \\
\text { encestarlo en un contenedor (caja). Tres alumnos hacen de } \\
\text { ratas y sacan de los contenedores la basura haciendo que } \\
\text { nunca para hasta la señal del profesor que hará que las ratas } \\
\text { desaparezcan y permita recoger la basura. } \\
\text { Adaptación: los alumnos con NEE realizan un circuito con un } \\
\text { solo aro y lanzan desde el aro a una canasta más baja. }\end{array}$} & \\
\hline \multicolumn{2}{|c|}{$\begin{array}{l}\text { Ante la gravedad de la situación, se reunió el Pleno del } \\
\text { Ayuntamiento decidiendo ahuyentarlas con veneno para } \\
\text { ratas. La rata "Serafina" dijo: "Esta gente se cree que } \\
\text { ahora somos tontas, nos quieren envenenar con queso } \\
\text { malo. Nos vamos a comer el queso y dejaremos el } \\
\text { veneno" } \\
\text { Se juega a queso y veneno. Divididos en dos grupos se } \\
\text { disponen todos en fila, dando la espalda al otro grupo. Cuando } \\
\text { el profesor diga queso, el equipo de los venenos debe intentar } \\
\text { coger a los quesos y viceversa. }\end{array}$} & \\
\hline \multicolumn{3}{|c|}{ PARTE FINAL } \\
\hline \multicolumn{2}{|c|}{ Hacer un dibujo sobre la sesión. } & \\
\hline
\end{tabular}




\section{Criterios de evaluación}

A continuación se presentan los criterios de evaluación. Además, se tuvo en cuenta los siguientes porcentajes para cada uno de los diferentes contenidos: $10 \%$ para los conceptuales, $60 \%$ para los procedimentales y $30 \%$ para los actitudinales.

\begin{tabular}{|c|c|c|}
\hline \multirow[t]{2}{*}{$\begin{array}{c}\text { Concreción de criterios de } \\
\text { evaluación }\end{array}$} & \multicolumn{2}{|c|}{ Vinculación } \\
\hline & Objetivo & Contenido \\
\hline $\begin{array}{l}\text { Es capaz de adoptar diferentes } \\
\text { roles. }\end{array}$ & $\begin{array}{l}\text { Interpretar una historia } \\
\text { y adquirir nuevos roles. }\end{array}$ & $\begin{array}{l}\text { Cuento "Queso y veneno" (C) } \\
\text { Descubrimiento y exploración } \\
\text { de las posibilidades expresivas } \\
\text { del cuerpo y del movimiento } \\
\text { (P) }\end{array}$ \\
\hline \multirow{2}{*}{$\begin{array}{l}\text { Realiza diferentes } \\
\text { desplazamientos, saltos y giros. }\end{array}$} & $\begin{array}{l}\text { Respetar el material y } \\
\text { las instalaciones. }\end{array}$ & \multirow{2}{*}{$\begin{array}{l}\text { Descubrimiento y exploración } \\
\text { de las posibilidades expresivas } \\
\text { del cuerpo y del movimiento } \\
\text { (P) }\end{array}$} \\
\hline & $\begin{array}{l}\text { Comprender y respetar } \\
\text { las normas de los } \\
\text { juegos. }\end{array}$ & \\
\hline \multirow{2}{*}{$\begin{array}{l}\text { Respeta todas las normas } \\
\text { implantadas para los diferentes } \\
\text { juegos y actividades y el } \\
\text { material utilizado. }\end{array}$} & $\begin{array}{l}\text { Conseguir una actitud } \\
\text { innovadora en la } \\
\text { resolución y estrategias } \\
\text { de las actividades. }\end{array}$ & \multirow{2}{*}{$\begin{array}{l}\text { Participación y comprensión } \\
\text { de reglas de juego y del aula } \\
\text { (P) } \\
\text { Conocimiento de nuestro } \\
\text { cuerpo y el entorno que nos } \\
\text { rodea (C) }\end{array}$} \\
\hline & $\begin{array}{l}\text { Desarrollar la } \\
\text { capacidad de trabajar } \\
\text { en grupo y autonomía. } \\
\text { Aprender a jugar en } \\
\text { equipo. }\end{array}$ & \\
\hline $\begin{array}{l}\text { Colabora, innova y participa en } \\
\text { todos los juegos y actividades }\end{array}$ & $\begin{array}{l}\text { Conseguir una actitud } \\
\text { innovadora en la } \\
\text { resolución y estrategias } \\
\text { de las actividades. }\end{array}$ & $\begin{array}{l}\text { Participación y comprensión } \\
\text { de reglas de juego y aula }(P)\end{array}$ \\
\hline $\begin{array}{l}\text { Respeta las normas de } \\
\text { reciclaje. }\end{array}$ & $\begin{array}{l}\text { Desarrollar la } \\
\text { capacidad de trabajar } \\
\text { en grupo y autonomía. }\end{array}$ & El medio ambiente $(\mathrm{C})$ \\
\hline
\end{tabular}

\subsection{Propuesta de intervención para segundo ciclo}

En esta propuesta para el segundo ciclo se trabaja el cuento motor de "Ratones y gatos" enfocado al primer nivel de segundo ciclo.

\section{Objetivos}

\begin{tabular}{|c|c|c|c|c|}
\hline \multicolumn{2}{|c|}{ Concreción de objetivos didácticos } & $\begin{array}{c}\text { Vinculación } \\
\text { OGA }\end{array}$ & $\begin{array}{c}\text { Vinculación } \\
\text { OGE }\end{array}$ & Competencias \\
\hline 1 & $\begin{array}{l}\text { Tomar conciencia de nuestro } \\
\text { cuerpo y el espacio que nos } \\
\text { rodea. }\end{array}$ & $\begin{array}{c}1,2 \text { y } 6 ; \\
\text { Educación } \\
\text { Física. }\end{array}$ & A, B, C & $\begin{array}{c}\text { Comunicación } \\
\text { lingüística. }\end{array}$ \\
\hline
\end{tabular}




\begin{tabular}{|c|c|c|c|c|}
\hline 2 & $\begin{array}{l}\text { Fomentar nuestro espíritu de } \\
\text { superación. }\end{array}$ & $\begin{array}{l}1,2 \text { y } 4 \\
\text { Educación } \\
\text { Física. }\end{array}$ & $A, B, C$ & $\begin{array}{l}\text { Competencia } \\
\text { matemática y } \\
\text { competencias }\end{array}$ \\
\hline 3 & $\begin{array}{l}\text { Interpretar una historia y adquirir } \\
\text { roles. }\end{array}$ & $\begin{array}{l}\text { 1, 2, 3, 4, 5, } 6 \\
\text { y 7; Educación } \\
\text { Física. }\end{array}$ & $\mathrm{B}, \mathrm{C}, \mathrm{E}$ & $\begin{array}{l}\text { básicas en ciencia } \\
\text { y tecnología. }\end{array}$ \\
\hline 4 & $\begin{array}{l}\text { Mejorar las posibilidades } \\
\text { expresivas del cuerpo. }\end{array}$ & $\begin{array}{c}1,2 \text { y } 4 \\
\text { Educación } \\
\text { Física }\end{array}$ & B & $\begin{array}{l}\text { Competencia } \\
\text { digital. }\end{array}$ \\
\hline 5 & $\begin{array}{llll}\begin{array}{l}\text { Respetar el material y } \\
\text { instalaciones. }\end{array} & & \text { las } \\
\end{array}$ & $\begin{array}{l}\text { 6; Educación } \\
\text { Física }\end{array}$ & $\mathrm{D}, \mathrm{K}, \mathrm{M}$ & $\begin{array}{l}\text { Aprender a } \\
\text { aprender. }\end{array}$ \\
\hline 6 & $\begin{array}{l}\text { Conocer diferentes formas de } \\
\text { realizar juegos y tareas motrices. }\end{array}$ & $\begin{array}{l}1,2 \text { y } 6 \\
\text { Educación } \\
\text { Física }\end{array}$ & $\mathrm{B}, \mathrm{K}$ & $\begin{array}{c}\text { Competencia social } \\
\text { y cívica. }\end{array}$ \\
\hline 7 & $\begin{array}{l}\text { Comprender y respetar las } \\
\text { normas de los juegos. }\end{array}$ & $\begin{array}{c}5 \text { y } 6 ; \\
\text { Educación } \\
\text { Física }\end{array}$ & $A, B$ & $\begin{array}{l}\text { Sentido de } \\
\text { iniciativa y espíritu } \\
\text { emprendedor. }\end{array}$ \\
\hline
\end{tabular}

\section{Contenidos}

\begin{tabular}{|c|l|c|}
\hline \multicolumn{2}{|c|}{ Concreción y secuenciación de contenidos } & $\begin{array}{c}\text { Vinculación con } \\
\text { OBJETIVOS } \\
\text { DIDÁCTICOS }\end{array}$ \\
\hline 1 & Historia sobre ratones y gatos. & 3,5 \\
\hline 2 & Conocimiento de nuestro cuerpo y el entorno que nos rodea. & $1,2,3,6,8$ \\
\hline 3 & Adaptación de juegos y actividades populares a nuestros intereses. & $4,7,9,10$ \\
\hline 4 & Trabajos cooperativos. & $1,8,10$ \\
\hline 5 & $\begin{array}{l}\text { Descubrimiento y exploración de las posibilidades expresivas del } \\
\text { cuerpo y del movimiento. }\end{array}$ & $1,2,6,8$ \\
\hline
\end{tabular}

\section{Criterios de evaluación}

\begin{tabular}{|l|l|l|}
\hline $\begin{array}{c}\text { Concreción de } \\
\text { criterios de } \\
\text { evaluación }\end{array}$ & \multicolumn{2}{|c|}{ Vinculación } \\
\hline \multicolumn{1}{|c|}{ Objetivo } & \multicolumn{1}{c|}{ Contenido } \\
\hline $\begin{array}{l}\text { Es capaz de adoptar } \\
\text { diferentes roles. }\end{array}$ & $\begin{array}{l}\text { Tomar conciencia de nuestro } \\
\text { cuerpo y el espacio que nos } \\
\text { rodea. }\end{array}$ & $\begin{array}{l}\text { Historia de indios y hombres de } \\
\text { caballería. } \\
\text { Conocimiento de nuestro cuerpo y } \\
\text { el entorno que nos rodea. } \\
\text { Descubrimiento y exploración de las } \\
\text { posibilidades expresivas del cuerpo } \\
\text { y del movimiento. }\end{array}$ \\
\hline $\begin{array}{l}\text { Realiza diferentes } \\
\text { desplazamientos, saltos } \\
\text { y giros. }\end{array}$ & $\begin{array}{l}\text { Mejorar las posibilidades } \\
\text { expresivas del cuerpo. }\end{array}$ & $\begin{array}{l}\text { Descubrimiento y exploración de las } \\
\text { posibilidades expresivas del cuerpo } \\
\text { y del movimiento. }\end{array}$ \\
\hline $\begin{array}{l}\text { Respeta todas las } \\
\text { normas implantadas } \\
\text { para diferentes } \\
\text { juegos y actividades y } \\
\text { el material utilizado. }\end{array}$ & $\begin{array}{l}\text { Respetar el material y las } \\
\text { instalaciones. }\end{array}$ & $\begin{array}{l}\text { Adaptación de juegos populares a } \\
\text { nuestros intereses. } \\
\text { Conocimiento de nuestro cuerpo y } \\
\text { el entorno que nos rodea. }\end{array}$ \\
\hline $\begin{array}{l}\text { Trabajos cooperativos. } \\
\text { cuerpo y el espacio que nos } \\
\text { rodea. }\end{array}$ & $\begin{array}{l}\text { Tdaptación de juegos y actividades } \\
\text { populares a nuestros intereses. }\end{array}$ \\
\hline
\end{tabular}




\section{Sesiones}

\section{UNIDAD DIDÁCTICA CURSO Y CICLO \\ MATERIAL \\ METODOLOGÍA (№ \\ DE PARTICIPANTES)}

Ratones y gatos

Segundo ciclo, primer nivel

Aros, picas, colchonetas, pañuelos, maquillaje, radio, CD de música, ladrillos de psicomotricidad.

Individual y grupal.

\section{PARTE INICIAL}

\section{DESCRIPCIÓN}

Érase una vez, hace mucho tiempo, un grupo de gatos callejeros que se hacían Ilamar de ratones que vivían en la ciudad llamados PARTE PRINCIPAL

El grupo de gatos callejeros tenían largos bigotes, garras afiladas y algún que otro, cicatrices en la cara, mientras que los ratones estaban muy limpios, tenían bigotes rizados y siempre iban perfumados.

Estamos sentados en dos círculos independientes. Los ratones se pintarán, mientras que los hombres de gatos se pintarán los bigotes y las cicatrices. Si terminan, pueden inventar un lema, o canción para cada vez que ganen un punto.

Todos los días, al amanecer iban al río que pasa por debajo del puente a beber agua, desayunaban $y$ posteriormente, realizaban un baile.

Los alumnos se mueven por el espacio y van siguiendo lo que hace su capitán. Si su capitán bebe agua del río estos lo imitan, si comen, hace como que comen, etc.

Una vez terminado el baile, fueron a sus casas $y$ recogieron sus cosas para ir a pasear. Cuando los ratones iban caminando, encontraron a los gatos vaciando las papeleras del parque y los ratones corriendo a regañarles para que pararan.

Jugamos al juego de la cadena, los ratones la quedan y deben pillar a los gatos. Cada vez que pillen a uno, estos se sientan en el suelo hasta que estén pillados todos. Luego se cambia.

Una vez los gatos aprendieron la lección, los ratones le ofrecieron ir a pasear juntos y cantar una canción.

Cada grupo tiene cinco minutos para inventar una canción relacionada con la amistad, el que invente la mejor anota un punto.

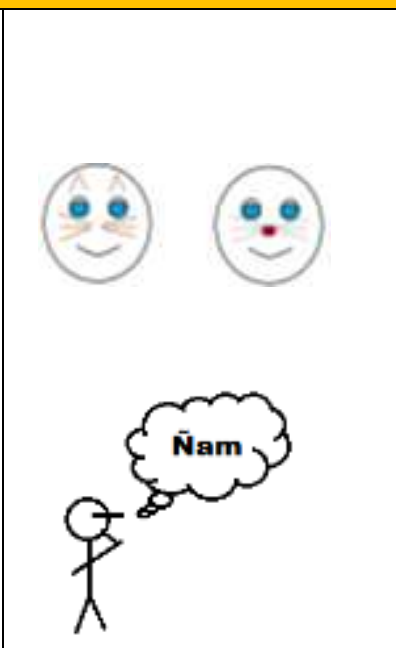

REPRESENTACIÓN
GRÁFICA
$\varnothing$
$\varnothing$

\begin{tabular}{|l|l|}
\hline \multicolumn{2}{|c|}{ PARTE FINAL } \\
\hline Hacer un dibujo sobre la sesión. & \\
\hline \multicolumn{2}{|c|}{} \\
\hline
\end{tabular}




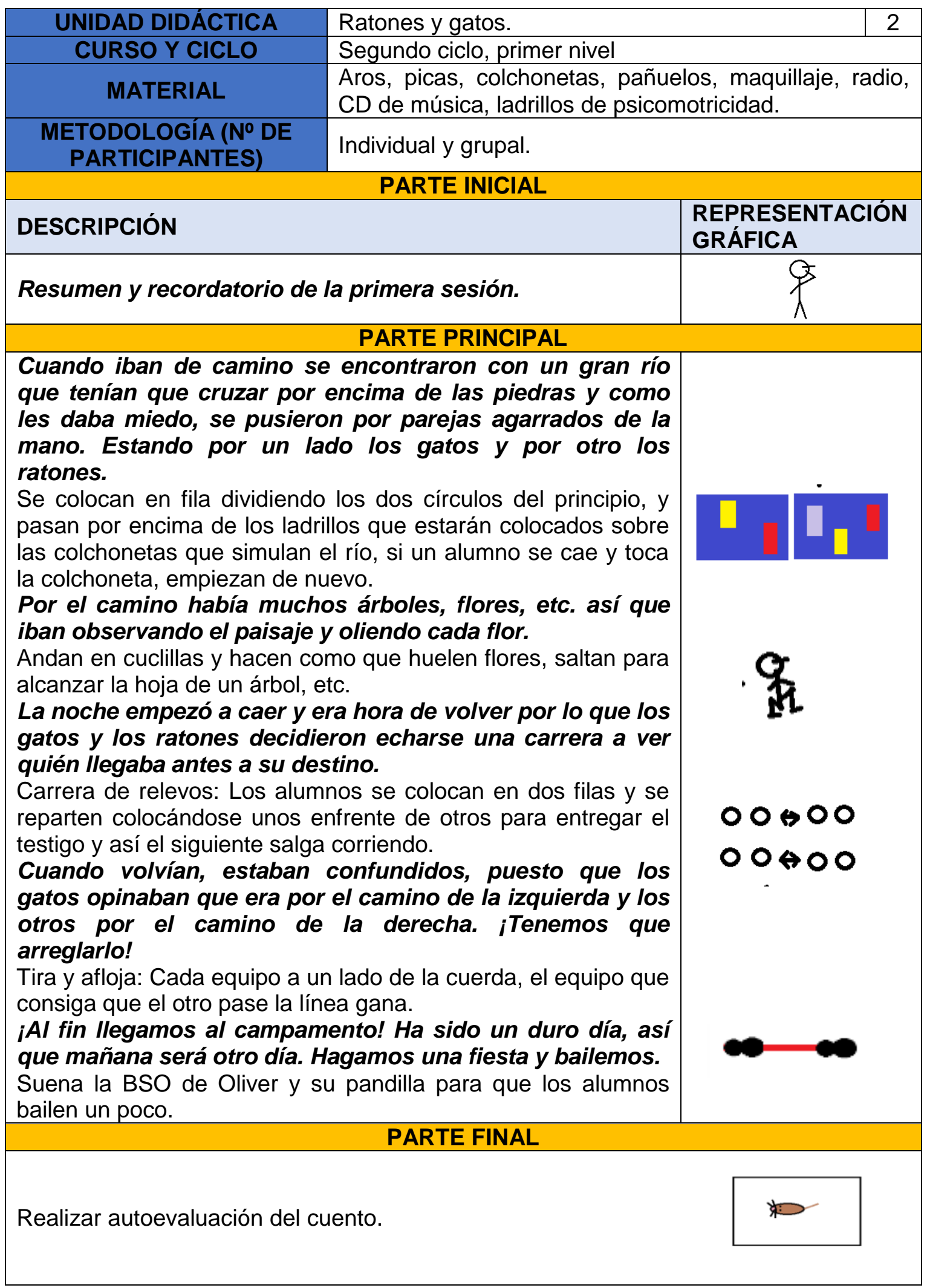




\subsection{Propuesta de intervención para tercer ciclo}

En esta propuesta para el tercer ciclo se trabaja el cuento motor de "Indios y hombres de caballería" enfocado al primer nivel de tercer ciclo ( $\left.5^{\circ}\right)$.

\section{Objetivos}

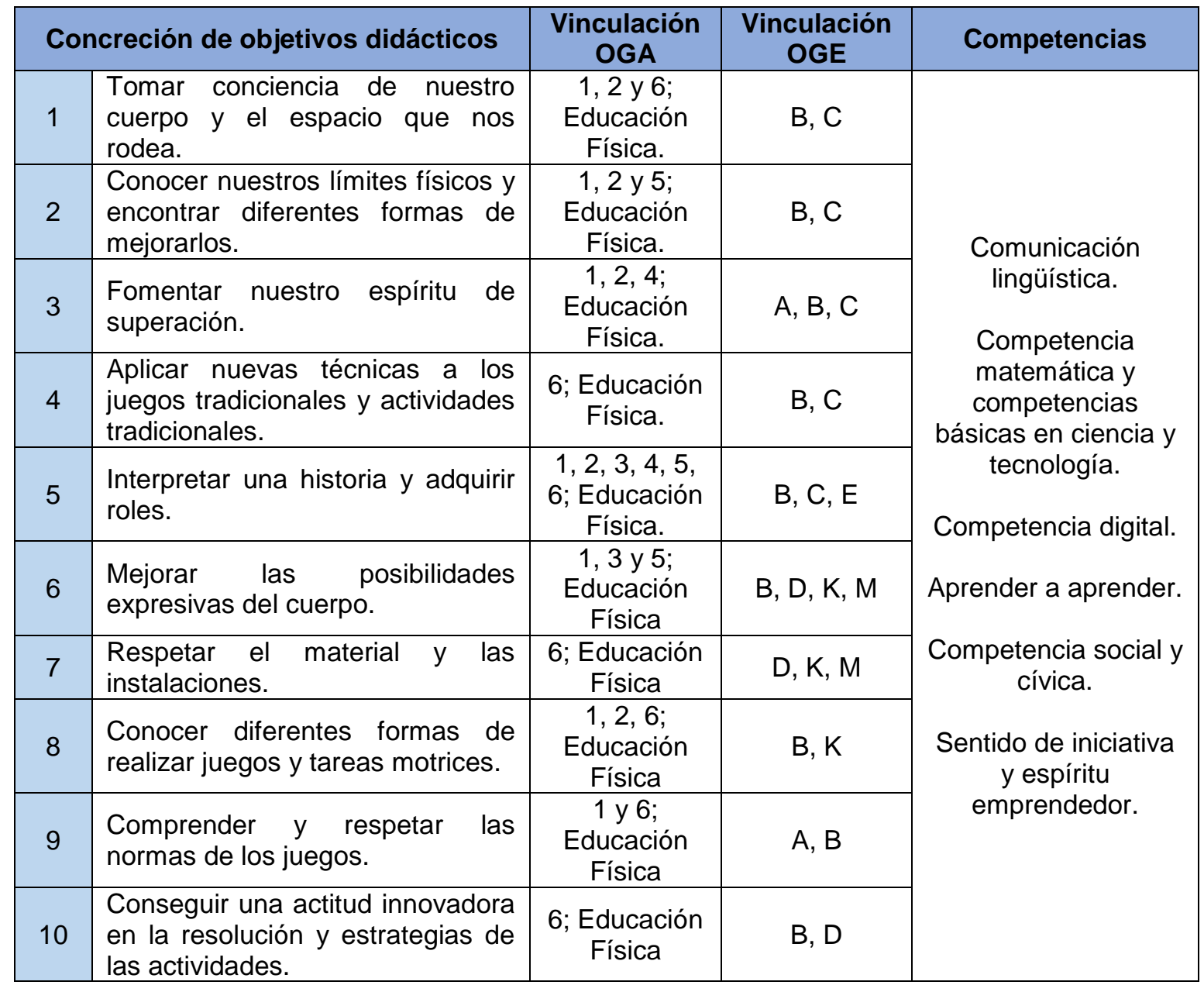

\section{Contenidos}

\begin{tabular}{|c|l|c|}
\hline \multicolumn{1}{|c|}{ Concreción y secuenciación de contenidos } & $\begin{array}{c}\text { Vinculación con } \\
\text { OBJETIVOS } \\
\text { DIDÁCTICOS }\end{array}$ \\
\hline 1 & Historia sobre indios y hombres de caballería. & 3,5 \\
\hline 2 & Conocimiento de nuestro cuerpo y el entorno que nos rodea. & $1,2,3,6,8$ \\
\hline 3 & Adaptación de juegos y actividades populares a nuestros intereses. & $4,7,9,10$ \\
\hline 4 & Trabajos cooperativos. & $1,8,10$ \\
\hline 5 & $\begin{array}{l}\text { Descubrimiento y exploración de las posibilidades expresivas del } \\
\text { cuerpo y del movimiento. }\end{array}$ & $1,2,6,8$ \\
\hline
\end{tabular}


Sesiones

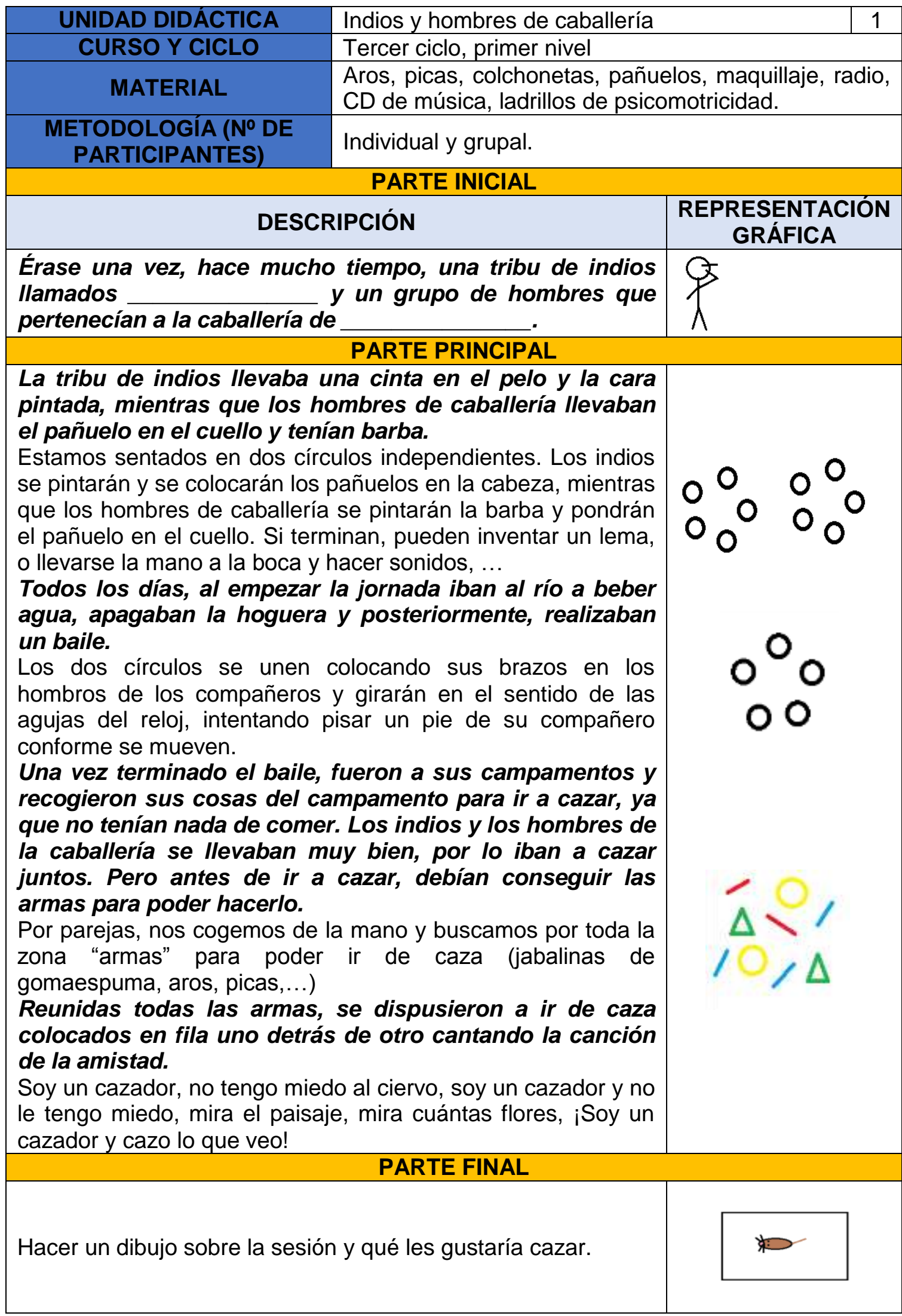




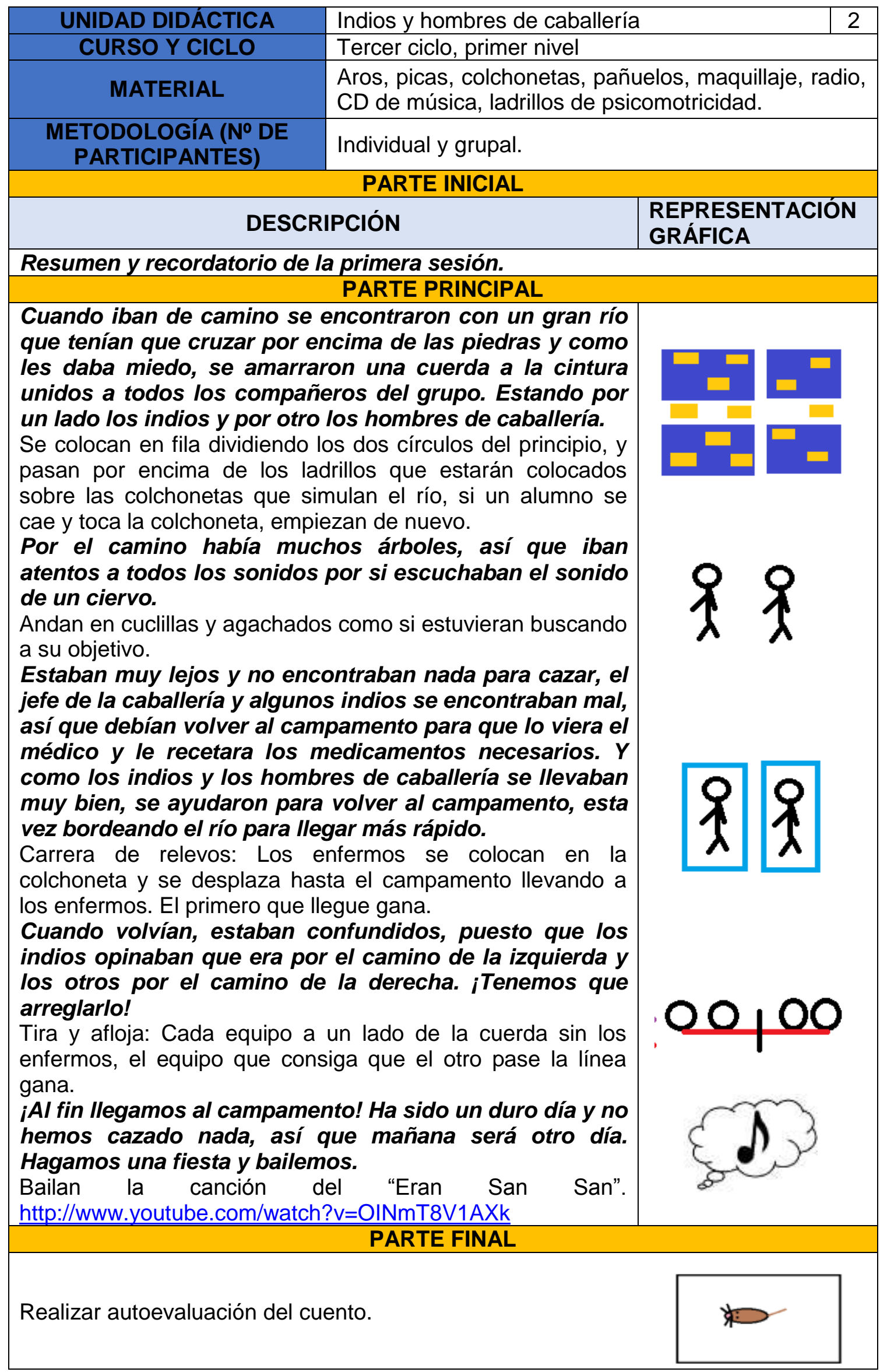




\section{Criterios de evaluación}

\begin{tabular}{|c|c|c|}
\hline \multirow{2}{*}{$\begin{array}{l}\text { Concreción de } \\
\text { criterios de } \\
\text { evaluación }\end{array}$} & \multicolumn{2}{|c|}{ Vinculación } \\
\hline & Objetivo & Contenido \\
\hline \multirow{3}{*}{$\begin{array}{l}\text { Es capaz de } \\
\text { adoptar } \\
\text { diferentes roles. }\end{array}$} & $\begin{array}{l}\text { Tomar conciencia de nuestro } \\
\text { cuerpo y el espacio que nos } \\
\text { rodea. }\end{array}$ & \multirow{3}{*}{$\begin{array}{l}\text { Historia de indios y hombres de } \\
\text { caballería. } \\
\text { Conocimiento de nuestro cuerpo } \\
\text { y el entorno que nos rodea. } \\
\text { Descubrimiento y exploración de } \\
\text { las posibilidades expresivas del } \\
\text { cuerpo y del movimiento. }\end{array}$} \\
\hline & $\begin{array}{l}\text { Fomentar nuestro espíritu de } \\
\text { superación. }\end{array}$ & \\
\hline & $\begin{array}{l}\text { Interpretar una historia y } \\
\text { adquirir nuevos roles. }\end{array}$ & \\
\hline \multirow{2}{*}{$\begin{array}{l}\text { Realiza } \\
\text { diferentes } \\
\text { desplazamientos, } \\
\text { saltos y giros. }\end{array}$} & $\begin{array}{l}\text { Conocer nuestros límites } \\
\text { físicos y encontrar diferentes } \\
\text { formas de mejorarlos. }\end{array}$ & \multirow{2}{*}{$\begin{array}{l}\text { Descubrimiento y exploración de } \\
\text { las posibilidades expresivas del } \\
\text { cuerpo y del movimiento. }\end{array}$} \\
\hline & $\begin{array}{l}\text { Mejorar las posibilidades } \\
\text { expresivas del cuerpo. }\end{array}$ & \\
\hline \multirow{3}{*}{$\begin{array}{l}\text { Respeta todas } \\
\text { las normas } \\
\text { implantadas para } \\
\text { los diferentes } \\
\text { juegos y } \\
\text { actividades y el } \\
\text { material utilizado. }\end{array}$} & $\begin{array}{l}\text { Respetar el material y las } \\
\text { instalaciones. }\end{array}$ & \multirow{3}{*}{$\begin{array}{l}\text { Adaptación de juegos populares } \\
\text { a nuestros intereses. } \\
\text { Conocimiento de nuestro cuerpo } \\
\text { y el entorno que nos rodea. }\end{array}$} \\
\hline & $\begin{array}{l}\text { Comprender y respetar las } \\
\text { normas de los juegos. }\end{array}$ & \\
\hline & $\begin{array}{l}\text { Conseguir una actitud } \\
\text { innovadora en la resolución y } \\
\text { estrategias de las actividades. }\end{array}$ & \\
\hline $\begin{array}{l}\text { Colabora, innova } \\
\text { y participa en } \\
\text { todos los juegos } \\
\text { y actividades }\end{array}$ & $\begin{array}{l}\text { Conseguir una actitud } \\
\text { innovadora en la resolución y } \\
\text { estrategias de las actividades. }\end{array}$ & $\begin{array}{l}\text { Adaptación de juegos populares } \\
\text { a nuestros intereses. }\end{array}$ \\
\hline $\begin{array}{l}\text { Lleva la ropa } \\
\text { adecuada. }\end{array}$ & $\begin{array}{l}\text { Tomar conciencia de nuestro } \\
\text { cuerpo y el espacio que nos } \\
\text { rodea. }\end{array}$ & $\begin{array}{l}\text { Conocimiento de nuestro cuerpo } \\
\text { y el entorno que nos rodea. }\end{array}$ \\
\hline $\begin{array}{l}\text { Consigue una } \\
\text { actitud } \\
\text { innovadora en la } \\
\text { resolución y } \\
\text { estrategias de las } \\
\text { actividades. }\end{array}$ & $\begin{array}{l}\text { Conseguir una actitud } \\
\text { innovadora en la resolución y } \\
\text { estrategias de las actividades. } \\
\text { Tomar conciencia del propio } \\
\text { cuerpo en relación con la } \\
\text { tensión, la relajación y la } \\
\text { respiración. }\end{array}$ & $\begin{array}{l}\text { Descubrimiento y exploración de } \\
\text { las posibilidades expresivas del } \\
\text { cuerpo y del movimiento. } \\
\text { Conocimiento de nuestro cuerpo } \\
\text { y entorno que nos rodea. }\end{array}$ \\
\hline $\begin{array}{l}\text { Toma conciencia } \\
\text { del propio cuerpo } \\
\text { en relación con la } \\
\text { tensión, la } \\
\text { relajación y la } \\
\text { respiración. }\end{array}$ & $\begin{array}{l}\text { Tomar conciencia del propio } \\
\text { cuerpo en relación con la } \\
\text { tensión, la relajación y la } \\
\text { respiración. }\end{array}$ & $\begin{array}{l}\text { Conocimiento de nuestro cuerpo } \\
\text { y el entorno que nos rodea. } \\
\text { Descubrimiento y exploración de } \\
\text { las posibilidades expresivas del } \\
\text { cuerpo. }\end{array}$ \\
\hline $\begin{array}{l}\text { Trabajos } \\
\text { cooperativos. }\end{array}$ & $\begin{array}{l}\text { Tomar conciencia de nuestro } \\
\text { cuerpo y el espacio que nos } \\
\text { rodea. }\end{array}$ & $\begin{array}{l}\text { Adaptación de juegos y } \\
\text { actividades populares a nuestros } \\
\text { intereses. }\end{array}$ \\
\hline
\end{tabular}




\begin{tabular}{|l|l|l|}
\hline $\begin{array}{l}\text { Respeta a los } \\
\text { compañeros. }\end{array}$ & $\begin{array}{l}\text { Comprender y respetar las } \\
\text { normas de los juegos. }\end{array}$ & $\begin{array}{l}\text { Conocimiento de nuestro cuerpo } \\
\text { y el entorno que nos rodea. }\end{array}$ \\
\hline $\begin{array}{l}\text { Interviene en el } \\
\text { proceso de } \\
\text { enseñanza- } \\
\begin{array}{l}\text { aprendizaje, } \\
\text { adoptando una } \\
\text { actitud positiva. }\end{array}\end{array}$ & $\begin{array}{l}\text { Fomentar nuestro espíritu de de } \\
\text { superación. }\end{array}$ & $\begin{array}{l}\text { Conocimiento de nuestro cuerpo } \\
\text { yel entorno que nos rodea. } \\
\text { Descubrimiento y exploración de } \\
\text { las posibilidades expresivas del } \\
\text { cuerpo. }\end{array}$ \\
\hline
\end{tabular}

\section{VALORACIÓN DE LA EXPERIENCIA}

A lo largo de la intervención se han ido recogiendo datos a través de los diferentes instrumentos de evaluación mencionados con anterioridad. Con ellos se han obtenido una serie de resultados a lo largo de todas las sesiones, las cuáles se muestran a continuación.

\subsection{Resultados de las sesiones del diario de prácticas}

Al realizar una lectura comparativa de cada uno de los días dedicados en el diario de prácticas sobre la puesta en práctica de los cuentos motores, se observa que en su inmensa mayoría les gusta la idea de imaginarse alguna historia e irla representando ellos mismos. Son pocos los niños que no les atrae esta metodología, coincidiendo con que son aquellos niños a los que sólo les atrae la idea de jugar al fútbol y consideran esta herramienta como un obstáculo para poder practicar su deporte favorito.

\subsection{Resultados de las autoevaluaciones}

A partir de las autoevaluaciones, se ha podido comprobar que esta herramienta metodológica ha tenido muy buena acogida entre los alumnos. En la Figura 1, se observan los resultados obtenidos a partir de las autoevaluaciones realizadas por los alumnos, después de realizar las sesiones pertenecientes al cuento motor. Como se puede observar, es en el tercer ciclo donde aumenta un poco el número de alumnos que no les ha gustado esta herramienta metodológica. Sin embargo, sigue siendo muy superior el número de alumnos a los que sí les ha gustado.
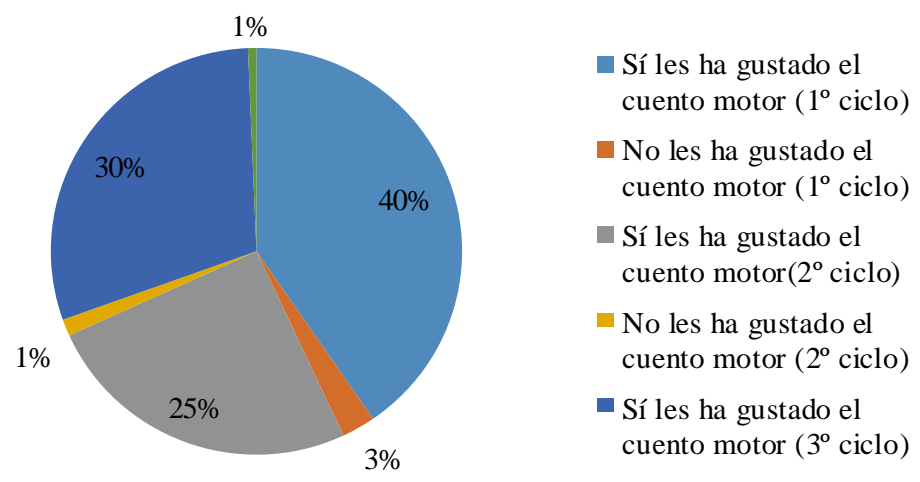

Figura 1. Porcentajes de éxito de los cuentos motores 
En la Figura 2, se contemplan aquellos resultados obtenidos a partir de la autoevaluación (Pregunta: ¿Te gustaría repetirlo con un cuento diferente?). Las respuestas han sido mayoritariamente positivas y les gustaría repetirlo. Encontrando también un número no muy amplio de alumnos que no les gustaría repetirlo, bajo la defensa de que con un cuento motor han tenido suficiente y prefieren practicar otro tipo de herramienta.

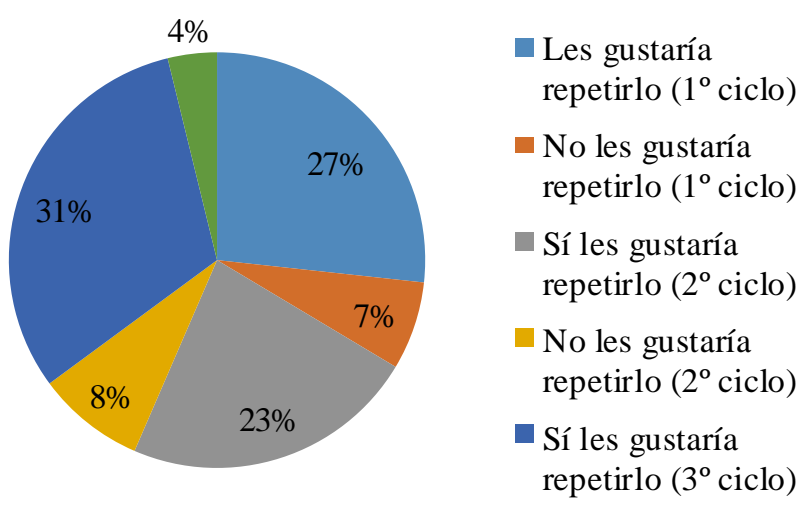

Figura 2. Porcentajes sobre si les gustaría repetir los cuentos motores

En la Figura 3, se muestra la percepción de lo que han aprendido los alumnos de primer ciclo tras la realización del cuento motor, destacando el reciclaje, seguido de un "muchas cosas" que englobaba el reciclaje, compartir material con los compañeros, etc.

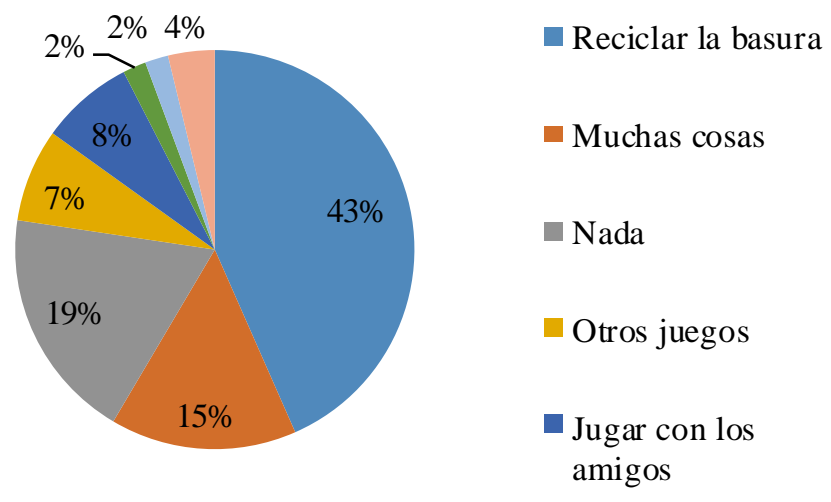

Figura 3. Porcentaje sobre lo aprendido en primer ciclo

Por otra parte, los alumnos de segundo ciclo defienden que en su mayoría han aprendido sobre el reciclaje y se les han aclarado conocimientos que antes no poseían al respecto (ver Figura 4). Pero aquí se encuentran un número de alumnos que no 
saben que han aprendido, por lo que se considera que no han aprendido nada nuevo al respecto.

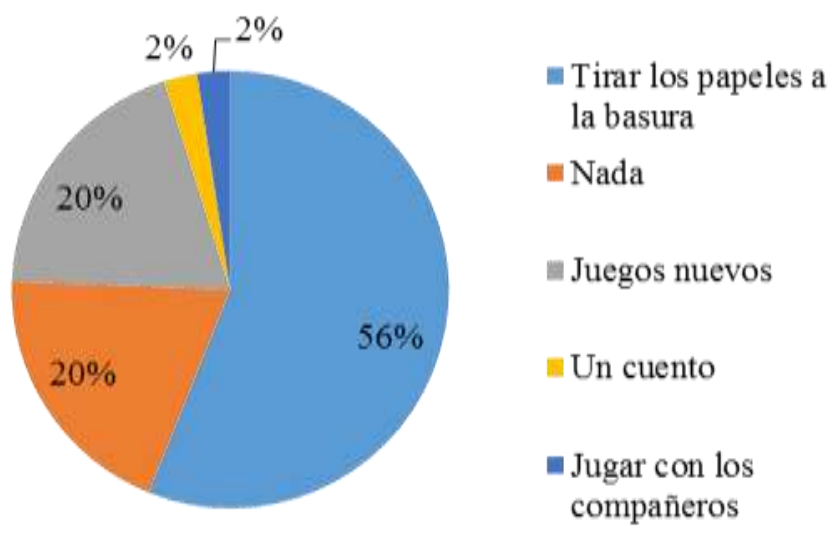

Figura 4. Porcentaje sobre lo aprendido en segundo ciclo

Para concluir el análisis de resultados a través de la autoevaluación del alumnado, en la Figura 5 se muestra que en tercer ciclo se encuentra una variedad mayor sobre la percepción del aprendizaje en las sesiones, destacando el apartado de "relacionarme con mis compañeros". Cabe destacar, que el cuento motor de tercer ciclo se diseñó en torno a los resultados obtenidos a través del cuestionario (ver anexo) e intentando mejorar el clima de clase, por la cantidad de conflictos que presentan ambos cursos

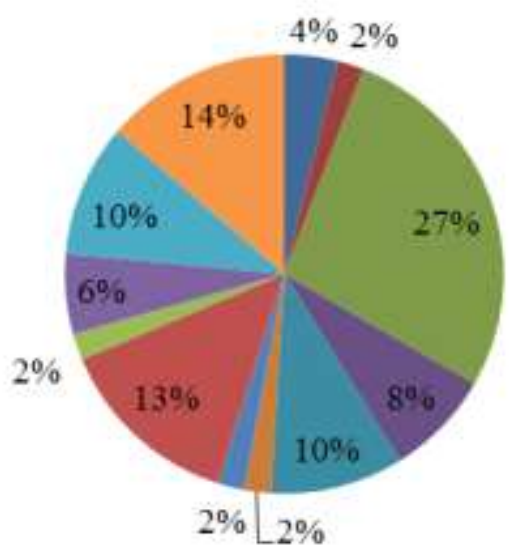

\author{
- Jugar a cosas nuevas \\ - Un tipo nuevo de \\ baile \\ n A relacionarme con \\ mis compañeros \\ - Compartir cosas \\ = Divertirse mediante \\ juegos
}

Figura 5. Porcentaje sobre lo aprendido en tercer ciclo

\title{
3.3. Resultados de las rúbricas
}

A partir de la visualización de las rúbricas de evaluación, se comprobó que todos los alumnos han obtenido muy buenos resultados. Hubo algunas excepciones, en los que los alumnos se mostraban poco participativos y tenían en algunos momentos un comportamiento inapropiado para su edad, por lo que nos veíamos obligados a castigarlos y al incorporarse habían perdido un poco la trama principal de la historia. 
Por último, se tomaron fotografías durante las sesiones con la finalidad de documentar las actividades y contrastar la información analizada con anterioridad a través de la técnica de observación. Como se puede observar en la Figura 6, el alumnado realizaba la actividad con más o menos intensidad, pero acorde a los que se les pedía, por lo que los resultados han sido muy positivos.

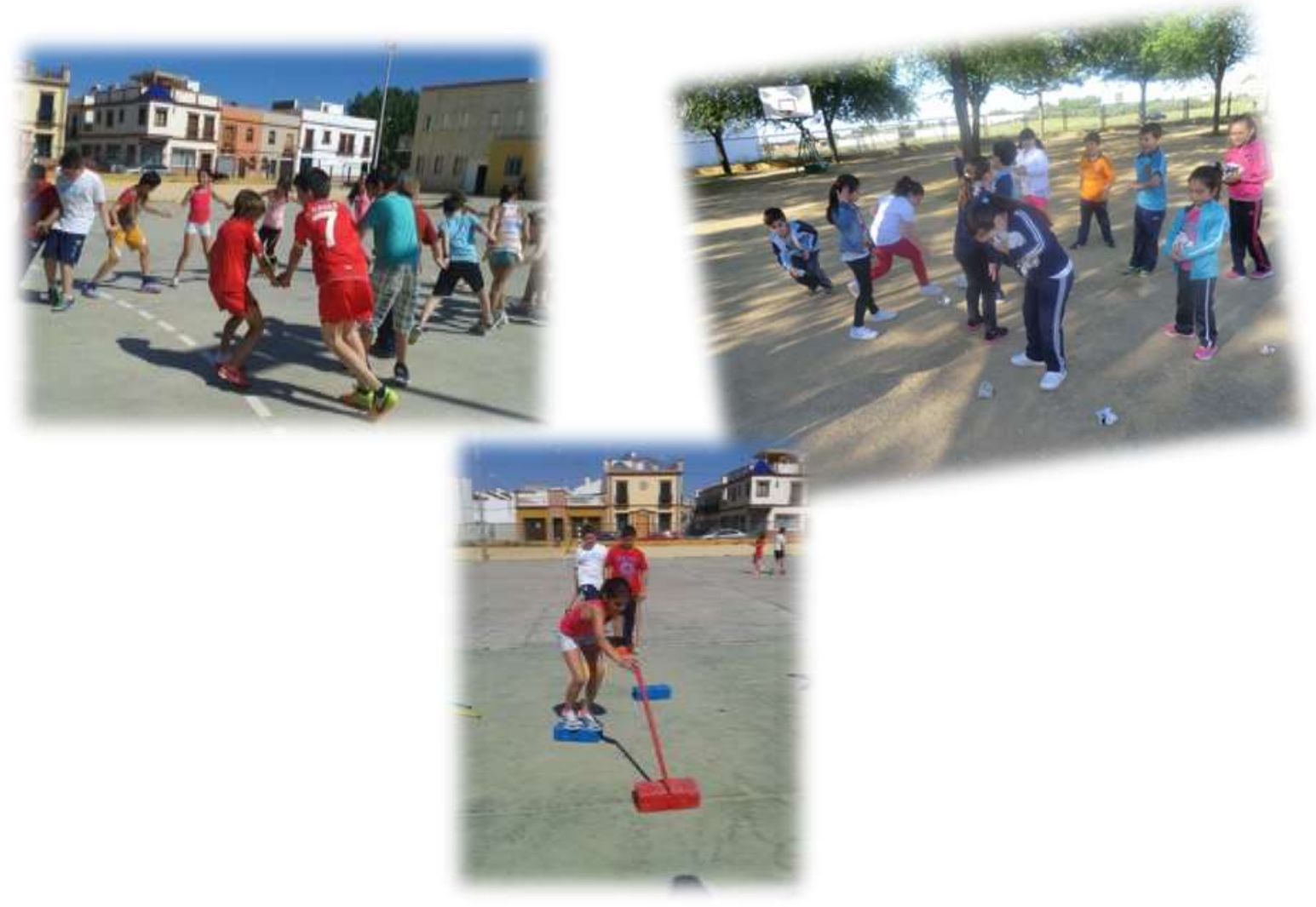

Figura 6. Fotografías tomadas durante el desarrollo de los cuentos motores

\subsection{Propuestas de mejora}

Tras finalizar la experiencia y analizar los resultados obtenidos, se han encontrado una serie de aspectos a tener en cuenta para mejorarla la próxima vez que se lleve a cabo. Así para conseguir llevar con éxito un cuento motor en las clases de EF, se presentan las siguientes recomendaciones:

- Dar unas pautas más claras en un futuro, o explicar con más detalle de qué se trata un cuento motor. Se busca con esto disminuir la pérdida del alumnado al comienzo del cuento con dudas sobre lo que deben hacer.

- Utilizar material más variado. El alumnado no conocía la mitad de los materiales de los que dispone el centro y emplear materiales nuevos puede generar una mayor motivación.

- Lectura del cuento completo antes de comenzar las sesiones del cuento motor. Esta propuesta tiene por objetivo, interesar a los alumnos en la actividad antes de su comienzo, por si no diera tiempo a realizar todas las sesiones de la unidad, al menos que conozcan la historia al completo. 
- Diseño de una batería más amplia de actividades. Había una serie de alumnos que acababan las actividades antes que el resto, por lo que podrían mantener una motivación más alta, si dispusieran de más ejercicios relacionados con la actividad.

- Dar protagonismo a aquellos alumnos que sean más conflictivos o estén apartados del grupo. Esto tiene por finalidad mejorar la integración de estos alumnos en el grupo, dándole un papel protagonista como ser capitán de un equipo o pintarse del color que quiera, por lo que su actitud mejorará considerablemente a lo largo de la sesión.

- Diseñar dinámicas para mejorar el clima de clase si fuera necesario. Si el clima de clase no es idóneo, se puede intervenir a partir del cuento introduciendo una dinámica para intentar solventar o mejorar el problema que tenga el grupo.

\section{CONCLUSIONES}

Este trabajo ha sido realizado con el objetivo de llevar a la práctica una herramienta metodológica nueva e innovadora, como son los cuentos motores. A partir de ellos, se ha buscado hacer las clases de Educación Física más dinámicas y amenas para todo el alumnado intentando aumentar por tanto su motivación.

En conclusión, el cuento motor se ha mostrado como una herramienta metodológica atractiva para emplearse en algunas clases de EF. Aunque los diferentes autores definen que los cuentos motores son más efectivos en las edades tempranas, tras la experiencia obtenida durante el periodo de prácticas y analizar los datos obtenidos, se ha mostrado unos resultados bastantes positivos en la puesta en práctica, por lo que se recomienda su uso como un recurso metodológico más en todos los ciclos. Sin embargo, consideramos fundamental para el éxito del uso del cuento motor, mejorar la formación de los docentes en este sentido, para asegurar su éxito pedagógico en las clases de EF de Primaria.

\section{REFERENCIAS}

Arguedas, C. (2006). Cuentos musicales para los más pequeños. Actualidades Investigativas en Educación, 6, 1-22. Recuperado de http://revista.inie.ucr.ac.cr/uploads/tx magazine/cuentossss.pdf

Bettleheim, B. (1995). Psicoanálisis de los cuentos de hadas. Barcelona. Ed. Crítica.

Conde, J. L. (1994). Los cuentos motores. (Vol I y II). Barcelona: Paidotribo.

Conde, J. L., y Viciana, V. (1999). Propuestas metodológicas para el desarrollo de las capacidades expresivas y de las habilidades motrices en educación infantil. En M. Arteaga, V. Viciana, y J. L. Conde, Desarrollo de la expresividad corporal. Tratamiento globalizador de los contenidos de representación (2 $2^{\underline{a}}$ ed.) (pp. 6181). Barcelona: INDE.

Decreto 97/2015, de 3 de marzo, por el que se establece la ordenación y el currículo de la Educación Primaria en la Comunidad Autónoma de Andalucía. Boletín Oficial de la Junta de Andalucía. Sevilla, 13 de marzo de 2015, núm. 50, pp. 1122. 
Del Barrio, D., Bustamante, R., Calzado, M. A., Nievas, J.M., Palomo, S., Prieto, A., Quiroga, J. J., Rodríguez, V. M., Vega, M., y Veira, E (2011). Cuentos motores en Educación Física Primaria. Érase una vez en... Educación Física. Barcelona: INDE.

Edwards, M. (2009). Algunas reflexiones sobre el concepto y características de la innovación educativa. Tendencias21. Innovación. Blog sobre invención y creatividad de Tendencias21. Recuperado de http://www.tendencias21.net/innovacion/Algunas-reflexiones-sobre-el-conceptoy-caracteristicas-de-la-innovacion-educativa a17.html

Iglesia, J. (2008). Los cuentos motores como herramienta pedagógica para la Educación Infantil y Primaria. Icono 14, 10, 1-15.

Ley Orgánica 2/2006, de 3 de mayo, de Educación. Boletín Oficial del Estado. Madrid, 4 de mayo de 2006, núm. 2103, pp. 97858-97921.

Méndez-Giménez, A. y Fernández-Río, J. (2013). El diseño de cuentos motores en la formación inicial del profesorado asturiano. Análisis de las creencias de los estudiantes desde la perspectiva construccionista. Revista de Investigación en Educación, 11(2), 111-122.

Molina, R. (2008). Los cuentos ayudan a crecer. Revista Digital: Innovación y Experiencias Educativas, 13. Recuperado de http://www.csicsif.es/andalucia/modules/mod ense/revista/pdf/Numero 13/REMEDIOS MOLI NA 2.pdf

Real Decreto 126/2014, de 28 de febrero, por el que se establece el currículo básico de Educación Primaria. Boletín Oficial del Estado. Madrid, 1 de marzo de 2014, núm. 52, pp. 19349-19420.

Ruiz, J. V. (2011). El cuento motor en la educación infantil y en la educación física escolar: cómo construir un espacio para jugar, cooperar, convivir y crear. Sevilla: Wanceulen.

Vargas, R., y Carrasco, L. (2006). El cuento motor y su incidencia en la educación por el movimiento. Pensamiento Educativo. Revista de Investigación Educacional Latinoamericana, 38, 108-124. Recuperado de http://pensamientoeducativo.uc.cl/index.php/pel/article/view/305/654

\section{Agradecimientos}

Este artículo es fruto de mi trabajo fin de grado (TFG) y me gustaría agradecer la ayuda y colaboración del que fue mi tutor, el Dr. Bartolomé J. Almagro. Por supuesto, también darle las gracias al centro, al maestro de EF y al alumnado; todos hicieron posible que desarrollase esta idea y mejorase mi formación. 